The most striking peculiarity of our fourth group of Gentiana is the sensibility of their flowers to the influence of the weather, which is apparently connected with the sensibility of their natural fertilisers to the same influence. The following observation clearly shows that different species differ widely in this sensibility, even when growing in the same locality. On the Piz Umbrail, July 16, I874, I had collected some plants of Gentiana bavarica, var, imbricata, and of G. verna, and put them in my sleeping-room in the Quarta Cantoniera, upon a plate filled with water. The next morning, at half-past four o'clock, I found the flowers of $G$. bavarica already opened, those of G. verna still closed. I placed the plate outside the window, where the intensity of light was at least as great, but the temperature much lower, and all the opened flowers began twisting. After they had closed, I brought them back into the room, and they opened again. Repeating this trial from half-past four to half-past six o'clock, I saw them two or three times closing and opening again. Gentiana verna, standing upon the same plate, during this time, had not yet opened a single flower.

From this observation, the further prosecution of which was prevented by my departure, it is obvious (I) that the opening of the flowers of these species of Gentiana is caused

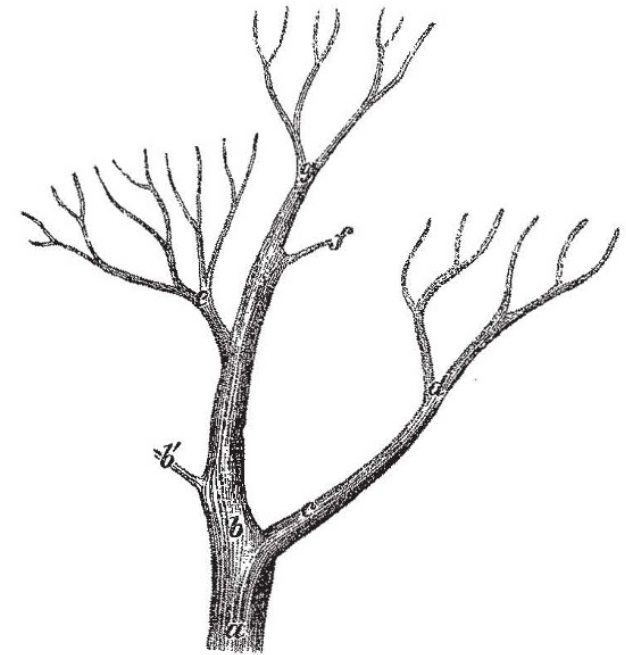

FrG. $\times 15$-Pedigree ot the species of Gentiana of Germany and Switzerland.

by heat, not by light; (2) that $G$. verna requires a higher temperature for opening than $G$. bavarica, var. imbricata. Possibly this is one of the causes which makes $G$. verna descend into sub-Alpine and low lands, whilst $G$. bavarica is confined to the Alpine region.

Comparing the present group with the foregoing ones, we need hardly doubt that it is most nearly allied to our second group, from which it differs only by the narrowness of the corolla, by the further development of the folds between the petals, and in connection with this by their greater sensibility, and by the lobes of the stigma being dilated. Gentiana prostrata, agreeing in every other respect with our fourth group, has as yet retained the two twisted stigma-branches, and therefore may be considered as a connecting species between the second group and the fourth, which is descended from it.

Summing up the above relations between the species of Gentiana of Germany and Switzerland, we obtain a pedigree like Fig. I I5, in which the signification of the lettering is as follows :-

(a) Hypothetical ancestral form with fully open flowers, twisted stigma-branches, diverging stamens, and honey secreted at the base of the flower in the angle between the base of the pistil and the corolla. From this ancestral form we see two branches $b$ and $c$ descend; $b$ with the nectary confined to the base of the pistil, $c$ with nectaries at the base of the coroila. From the branch $c$ has developed the sub-genus Entotricha Frolich $(d)$, containing six species:-G. campestris, germanica, amarella, obtusifolia, tenella, and nana, adapted both to Apidæ and to Lepidoptera. Of the branch $b$ an original form, $G$. lutea $\left(b^{\prime}\right)$, has been preserved, accessible to insects of all orders, but from the same branch has descended the large sub-genus Colanthe Frœlich (e), containing eleven species :--G. punctata, pannonica, purpurea, cruciata, asclepiadea, Pneumonanthe, Fiolichii, frigida, acaulis, excisa, and ciliata, all adapted to humblebees. One branch of this sub-genus $(e)$, by narrowing the corolla, perfecting the folds between the petals, dilating the stigma-branches, and thus adapting the flowers to Lepidoptera, has further developed the sub-genus Cyclostigma $(g)$, containing seven species :-G. bavarica, verna, astiva, imbricata, pumila, utriculosa, and nivalis. As a link between the ancestral sub-genus $(e)$ and the derived subgenus $G$, has been preserved $G$. prostra $a(f)$. Lippstadt HERMANN MÜLLER

\section{RECENTLY PROPOSED IMPROVEMENTS IN MUSICAL INTONATION}

THE harshness of the present system of tuning has been a source of constant complaint since it was first introduced, about a century and a half ago. But of late years several more or less practical attempts have been made to overcome this defect without interfering with the quality of our musical tones. Instruments with fixed tones, as the organ, piano, and harmonium, lead voices, and the inalterable quality of vocal tone has therefore to be constantly kept in view. The instruments exhibited in the Loan Collection of Scientific Apparatus at South Kensington are enough to show both the objects aimed at and the nature of the mechanical appliances by which it is hoped they may be more or less reached. It is difficult to give an intelligible account of them within the compass of an article, but Dr. Stone's two lectures ${ }^{1}$ and Mr. Bosanquet's more recent work ${ }^{2}$ will supply details and figures.

On examining musical tones generally, ${ }^{3}$ we are led to the conclusion that the first requisite is to have a succession of notes forming perfect Octaves, Fifths, and major Thirds, that is, making numbers of vibrations which the air executes during the same length of time in the ratios $1: 2,2: 3$, and $4: 5$ respectively. An examination of prevailing systems of modulation, has shown ${ }^{4}$ that a strict fulfilment of this condition would require $I I 7$ notes to the Octave-a mechanical impossibility on any instrument with fixed tones. Such a scheme must, however, be made the basis of subsequent work. Moreover if combinations with what is called the harmonic Seventh or $6: 7$ be admitted, then we should require very nearly to double the above number of separate notes. It follows, therefore, that we must either restrict our desires of modulation (which is not likely to happen) or be content to use more or less imperfect intervals, and the question turns upon the degree of endurable imperfection. It must be remembered that these apparently innumerable delicacies of sound present no real difficulty to the singer or violinist when he once knows the theory on which they have to be produced, for they are all generated by extremely simple intervals. The difficulty, indeed, is to avoid them, especially in part music, and to put up with alterations, apparently arbitrary and certainly neither

$x$ " Sound and Music," by Dr. W. H. Stone, in the series of Science Lectures at South Kensington, 1876 , pp. 46 . (Macmillan.)

$z$ "An Elementary Treatise on Musical Intervals and Temperament, with an Account of the Enharmonic Harmonium Exhibited in the Loan Collection of Scientific Instruments, South Kensington, $x 87^{6}$; also of an Enharmonic Organ Exhibited to the Musical Association of London, May, 1875," pp. 94, 1876 . (Macunillan.)

(1) "Sensations of Tone."

4 See my translation of Helmholtz, pp. $669-672$. 
easy to conceive nor to produce. No temperament, as such a makeshift intonation is called, could exist except by help of an instrument with fixed tones, and the most practised tuner finds it impossible to produce a satisfactory result, except by mechanical means. ${ }^{1}$ How then could we expect a singer to produce at will any of the fifty or more schemes of tuning that have been invented, or even either of the only two that have been a success, the mean-tone and the equal temperaments ? ${ }^{2}$

The Greek system of intonation, as we know from Euclid's "Section of the Canon," consisted of a series of perfect Fifths, and may for convenience be represented by $F, C, G, D, A, E, B$, where it will be found that each note is a Fifth higher than the preceding. It is therefore the simplest and most intelligible that can be imagined, and is in fact at the base of all music. Reduced to the same Octave and played as a major scale this gives C, D, E, F, G, A, B, C. This is perfectly singable, and produces excellent melodic effects. But if we attempt to play the usual major and minor chords of the scale with these notes, as F A C, C E G, G B D, DF A, A C E,

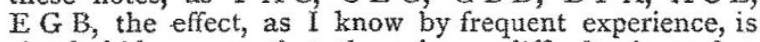
simply hideous, so that there is no difficulty in understanding why the Greeks called Thirds "dissonances" (diaphöna), and had no harmony. Observing that in the series of Fifths $E$ is the fourth Fifth above $C$, we may therefore say that the major Third cannot be identified with the fourth Fifth up, reduced to the same Octave. On calculating out the ratio we find $\mathrm{C}: \mathrm{E}=4: 5 \times \frac{81}{80}$, whereas the real corsonance requires $4: 5$. This would be produced by taking a note $E_{1}$, as we may write it, which is flatter than $E$ in the ratio of $80: 8 \mathrm{r}$. The result of carrying this out to the extent of modern modulation is the series of II 7 notes to the Octave already mentioned.

In the Loan Collection, one instrument, General Perronet Thompson's enharmonic organ, grappled with this problem to the extent of forty notes. ${ }^{3}$ But its three finger-boards with occasional extraordinary shapes and colours to the finger keys (figured by Dr. Stone, op.cit., p. 32) might well frighten the uninitiated. Yet General Thompson, himself unable to play, taught a blind organist how to use it, so that in a fortnight she could perform in public, and I have often heard the instrument played by others, who did not complain of any difficulty. Helmholtz (in my

× "Mr Ellis has given a practical rule," [for producing the usual, intentionally equal, temperament], "which does not err in its results by much more than the hundredth part of a semitone." (Seldom as much as that.) "It is-make all the Fifths which lie entirely within the Octave $c^{\prime} c^{\prime \prime}$ [middle $C$ to the $C$ above] beat ontec per second; and make those which have their upper notes above $c^{\prime \prime}$ beat three times in two seconds. Keeping the Fifth $f^{\prime}-c$ " to the last, it should beat once in between one and two seconds. Ste
Ellis's "Helmholtz," p. 785 . This is a perfectly practicable rule, and tuners ought to be instructed in the use of it. There are few tuners who can prodace a tolerable equal temperament." -Bosanquet, op. cit., p. 5 . dace a tolerable equal temperament. (Proc. Roy. Soc, vol. xii., pp. 404-422),
2 See my paper on Temperament
where more than fifty schemes are calculated and analysed. Mr. Bosanquet where more than fifty schemes are calculated and analysed. Mr. Bosanquet
has a most interesting chapter on the history of the mean-tone temperament has a most interesting chapter on the history of the mean-tone temperament or old organ tuning, the only one known to Handel, and its complete realisa. t.on, without its former "wolves," by means of his own fingerboard, pp. 24-40. He rightly considers this temperament most suitable for the organ (p. 58) as the equal temperament is for the pianoforte. But then the volces of a choir might be led by the completed mean-tone system without
chords, which are shivered by the equal temperament.

3 chords, which are shivered by the equal temperament.
3 These are given by Mr. Bosanquet, op. cit., p. 22, arranged according 3 These are given by Mr. Bosanquet, $o p$. cit., p. 22, arranged according
to his own finger-board, which completely does away with the terrors of the to his own finger-board, which completely does away with the terrors of the
original, but also expressed in his own notation, which implies a temperament original, but also expressed in his own notation, which implies a temperament
which General Thompson well knew and repudiated. Hence $I$ add them which General Thompson well knew and repudiated. Hence $I$ add them
here in my own symmetrical arrangement (Proc. Roy. Soc., December, 1874 , here in my own symmetrical arrangement (Proc. Roy. Soc., December, 1874 ,
yol. xxiif. p. 29 , called "the simplest" by Mr. Bosanquet, p 5o), in which vol. $x$ xiii. p. 29 , called "the simplest" by Mr. Bosanquet, p 50 ), in which
the columns represent ascending Fifths, and the lines from left to right the columns represent ascending Fifths, and the lines from left to right
ascending major'Thirds, and where the superior and inferior numbers indicate ascending major Thirds, and where the superior and inferior numbers indicate
sharpening or flattening by a comma (this is here published for the first sharpe
time).

General P. Thompson's Enharmonic System :-

\begin{tabular}{|c|c|c|c|c|}
\hline 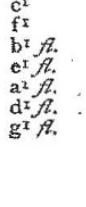 & $\begin{array}{l}\mathrm{e} \\
\mathrm{a} \\
\mathrm{d} \\
\mathrm{g} \\
\mathrm{c} \\
\mathrm{f} \\
\mathrm{b} f . \\
\mathrm{e} f . \\
\mathrm{e}, \mu .\end{array}$ & $\begin{array}{l}c_{x} s h, \\
f_{z} s h . \\
b_{x} \\
e_{x} \\
a_{I} \\
d_{I} \\
g_{z} \\
e_{1} \\
f_{I}\end{array}$ & $\begin{array}{l}\mathrm{a}_{2} \text { sh. } \\
\mathrm{d}_{2} s h . \\
\mathrm{g}_{2} s h . \\
\mathrm{c}_{2} \text { sh. } \\
\mathrm{f}_{2} \text { sh. } \\
\mathrm{b}_{2} \\
' \mathrm{c}_{2} \\
\mathrm{a}_{2}\end{array}$ & $\begin{array}{l}\mathrm{f}_{3} s s h . \\
\mathrm{b}_{3} s h . \\
\mathrm{e}_{3} s h . \\
a_{3} s h . \\
d_{3} s h . \\
\mathrm{g}_{3} s h . \\
\mathrm{c}_{3} s h .\end{array}$ \\
\hline
\end{tabular}

translation, p. 636), who also heard it played, speaks of its chords as "extraordinarily harmonious," but the quality of tone (one stop of "metal principals") did not distinguish the consonances effectually at all times, and the compass of forty tones of course materially limited modulation except into tonic and relative minors, which were well provided for.

Mr. Colin Brown has also grappled with perfect tertian harmony, but has exhibited only a model of his keyboard, figured and described by himself in Dr. Stone's book (ib. pp. 42-45). ${ }^{1}$ His scheme allowed of sufficient modulation into the dominant and sub-dominant major keys, and their first relative minors, but almost utterly ignored the tonic minor, and further minor modulation. As the instrument is an harmonium, the quality of tone is remarkably suitable for bringing out the effects of perfect Fifths and Thirds, and when proper music was selected, the result was most satisfactory. The keyboard is much simpler than General Thompson's, and has the great advantage of being the same in all keys. Such an instrument is of the highest value for lecture illustrations of harmony, and for training of vocalists in perfect intoration. As an independent instrument, is power of modulation is too limited, and the fingering usually simple enough, occasionally becomes very troublesome. ${ }^{2}$

These are the only instruments on which perfect tertian harmony was attempted. In the others some sort of compromise was come to. Mr. Guéroult showed his modification of Helmholtz's double keyboard, each finger-key being cut in half, and the upper half giving, generally, a note flatter than the lower half by a comma. ${ }^{3}$

This is a most convenient instrument for scientific purposes, but from its very limited capacity not so well suited as even Mr. Colin Brown's for playing musical pieces. The fingering is also full of difficulty, having all the imperfections of the ordinary board, with many others superadded, and differs in every key.

We have seen that if we use the fourth Fifth up from any note, when reduced to the same Octave, as the major Third, it is too sharp by a comma, and unbearably dissonant, but if we use the eighth Fifth down, also reduced to the same Octave, the result is a note just $\frac{x}{11}$ comma too flat, which is very much closer than the major Third in actual use (for that is $\frac{7}{71}$ comma too sharp), and is not at all disagreeable, although not by any means as pleasant as the perfect major Third. Thus, going down eight perfect Fifths from $\mathrm{C}$, we get in succession $\mathrm{F}$, B $f$., E $f$., $\mathrm{A} f$. $\mathrm{D} f$., $\mathrm{G} f ., \mathrm{C} f$., and $\mathrm{F} f$., and the proposal is to use $\mathrm{F} f$. for $\mathrm{E}_{1}$. On the piano, and all instruments in the usual temperament, these are the same notes, but they are not so when thus tuned, and they are still strictly distinguished in our usual musical notation. Herr Georg Appunn, to whom we are indebted for various excellent acoustical apparatus, and especially for a tonometer (exhibited in the Loan Collection), which is self-verifying, and enables us to measure pitch with wonderful accuracy, likewise showed an harmonium, consisting of three rows of keys, the upper ones in the form of studs, with practically the usual fingering, consisting of thirty-six tones

${ }^{x}$ The notes used in the figure are comprised in the second, third, and fourth columns of the above scheme of General P. Thompson's, but carried further, the second column rising to $D$ sh, and descending to $F$, $f$., the third rising to $B_{1}$ sh, and descending to $A_{2} A_{h}$, and the fourth xising to $A_{3} s s h$, and descending to $G_{3}$, giving fifty-two notes in all; but the instrument performej on at Dr. Stone's lecture (July 25, 1876) had not so large a compass.

2"It is clear that this (Mr. C. Brown's) arrangement adapts itself with some facility to all music in which there is not much modulation, or in which the modulation is of a simple type. It is, however, easy to give instances which will at once involve the performer in difficulties." Bosanquet, $o p$. cit 48-9. Mr. Bosanquet, who is a practised organist, having studied the finger-
ing, and played on the instrument at the Glasgow Meeting of the British

Association, is well able to speak to its capabilities.
3 Disregarding one very slight alteration, the compass of twenty-four notes extended from $\mathbf{E} / f$. to $B$ in the second column of General Thompson's, from $\mathrm{G}_{1}$ to $\mathrm{G}_{1}$ sh. in the Third, and from $\mathrm{F}_{2}$ sh. to $\mathrm{B}_{2}$ sh. in the Fourth. With the exception of Two Fifths ( $\mathrm{G}_{1}$ sh. to $\mathrm{E} / f_{2}$, taken to be $\mathrm{D}_{1}$ sh... ; and $\mathrm{B}_{2}$ sh. to $\mathrm{G}_{1}$ taken at $F_{2} s s h$.), which were too flat by ${ }_{1}{ }_{1}$ of a comma, as all Fifths ought to be on the piano, this gave a complete succession of dominant modulations, but only admitted of five minor keys. 
forming thirty-five perfect Fifths, which, by the contrivance of using the eighth Fifth down as the major Third, into the place of which its finger-key is placed, gives very free play for modulation in all directions with perfect uniformity, although of course slightly imperfect intonation. 1

To this system of perfect Fifths and major Thirds identified with eight Fifths down, we must attach all the other contrivances for reducing the number of notes necessary to tertian harmony, without seriously offending the ear. The practicability of arranging any number of dozens of such notes in the Octave, up to at least seven dozen, so that they should be entirely under the command of the performer, be fingered precisely in the same way in all keys, and have a style of fingering which is of about the same difficulty as that for three sharps or three flats on the piano, has been proved to demonstration by the "generalised keyboard" of Mr. Bosanquet, exhibited at the Loan Collection, for his enharmonic harmonium, and, up to four dozen finger keys to the Octave, to the Musical Association upon his enharmonic Organ.2 This keyboard is quite a triumph of ingenious construction, founded on rigorously scientific principles, for the practical solution of an apparently insoluble problem.

The modifications of the perfect Fifth system (to which Mr. Bosanquet seems much inclined, op. cit., p. 57) depend on the discovery that fifty-three perfect Fifths exceed thirty-one Octaves by only about $\mathrm{i} 3 \frac{6}{00}$ of an equal semitone, or very nearly $\frac{2}{11}$ of a comma. Helmholtz proposed to reduce every Fifth by $\frac{3}{88}$ of a comma. This would make fifty-three of the flattened Fifths to be about is of a semitone less than thirty-one octaves, too large an interval for good ears not to perceive, being nearly half a comma, but then all his Fifths would be audibly perfect, and all his major Thirds absolutely perfect. Mr. Bosanquet endeavoured to tune a stop on his enharmonic organ in that way, but the effect with stopped pipes did not repay the immense trouble of tuning (ibid.), which cannot be truly effected without much mechanical assistance, and is therefore generally impracticable.

The great difficulty of tuning is also an objection which applies to Mr. Bosanquet's own proposal to divide the Octave absolutely into fifty-three parts (see op. cit., p. 56). This would flatten the Fifth still less, but of course would also make the major Thirds nearly as flat as those in the system of perfect Fifths, from which his differ only by about $\frac{1}{4}$ of a comma. It is not likely that $\mathrm{Mr}$. Bosanquet has been able to tune to such a degree of accuracy. And as the object of the division of fifty-three is only to modulate ad infinitum, such accuracy is needless for general purposes, for which forty-eight perfect Fifths (or, as I believe, six sets of eight perfect Fifths, differing by perfect major Thirds from each other, and hence comparatively easy to tune by Fifths and check by Thirds), would fully suffice. ${ }^{3}$

x The notes may be considered to be those in Gen. Thompson's second column continued up to Ash. and down to A ffft. (or A quadruple flat), the names being altered to those of the finger-keys corresponding to those on the ordinary piano, so that no more sharps and flats are used than in ordinary notation. Unfortunately the bellows and some parts of the mechanism were injured in the carriage, and hence the full effect could not be appreciated. There were two extra rows of keys to bring out Herr Appunn's favourite minor Third, $16: 19$, which is slightly closer than that on the piano, and yery effective in certain cases, but the fingering for these was

new and difficult, and could not be considered practical. quet's book (op. cit.. p. 23), where it is fully described, and is also explained quet's book (op. cit.. p. 23), where it is fully described, and is also explained at length in my Helaholt, p. $692-690$. In and address are given, with his prices for compasses of two to seven dozen keys per Octave. Such instruments are indispensable for the

3 See the full explanations in my Helmholtz, pp. 655, 657, 783. Tuning by perfect intervals is the only system practicable witnout mechanical assistance. But even to tune the thirty-five Fifths of Appunn is impossible by ear alone. I find tuners have a difficulty with only eight notes, forming seven successive Fifths. But when the next eight notes are taken as major 'Thirds to these, all verihed by forming Fifths with each other and producing correct differential tones with the original set, we may hope for some correctness. The only really satisfactory way of tuning is by calculating the pitch of each note, and then causing a set of forks, or Appunn reeds, to be
The instruments exhibited in the Loan Exhibition and the others indicated in the preceding lines may, therefore, be said to have practically solved the difficulty of tertian harmony on instruments with fixed tones, and they have even approached to a solution for septimal harmony (which uses the harmonic Seventh; see Bosanquet, $o \not p$. cit., p. $4 \mathrm{I}$ ). Voices in part music, when unaccompanied, must sing in just tertian or even septimal harmony, but when accompanied they will inevitably follow the instrument. Violinists can do what they like, but are too much inclined to Greek intonation, which is all very well by itself, but which the performer should learn to modify by something better than a rule of finger, in double-stopped passages and part music. With the bass the comma stop may be made effective to a great extent, and Dr. Stone is trying what he can do with the oboe and clarinet (op. cit., p. 35), so that there are some hopes of improving even the orchestra. Enough, at least, has been done on the instruments mentioned and in the practice and system of study of the Tonic Solfaists (Helmholtz, p. 640) to show that it is practically possible greatly to improve musical intonation.

AleXANDER J. ElLiS

\section{ON PHOTO-CHEMICAL PROCESSES IN THE RETINA}

$\mathrm{N}$ an article which lately appeared in NATURE (vol. xv., p. 308), I gave an account of certain very remarkable discoveries made by Prof. Kuihne, of Heidelberg, which added additional interest to the startling announcement contained in a recent communication made by Prof. Boll, of Rome, to the Berlin Academy, to wit, that the external layer of the retina is, during life, of a purple colour, which disappears at death, but which is, during life, continually being bleached by the action of light. In my first communication I stated that the account of Boll's researches which I was able to give, was only quoted at second-hand from Kühne's paper, as the number of the Proceedings of the Berlin Academy containing Boll's communication ${ }^{1}$ had not yet reached Manchester. Having now had the opportunity of reading that communication, I am able to state that the summary of it contained in my first article was correct in every particular. As the paper is, however, one of peculiar importance I propose, with the concurrence of the Editor of NAJURE, to insert a verbatim translation of it in next week's number of NATURE.

It is with great surprise that I have heard that the prominence given to Prof. Kühne's researches on the "Vision-purple" in my article in NATURE has given some pain to Prof. Boll, who probably feels some disappointment in not having been allowed to remain in sole possession of the promising field of research upon which he had entered. It is with still greater surprise, however, that I have read the remarks which $\mathrm{D}$. Warlemont, editor of the Annales d'Oculistique, has added to the literal trans" lation of my article which he has published in that journal, ${ }^{2}$ and which follows a brief abstract:of Boll's paper.

"Nous appelons toute l'attention de nos lecteurs sur les deux articles qu'ils viennent de lire, et qui signalent une découverte propre à révolutionner la physiologie de la rétine, à renverser quelques unes des idées reçues, à en affirmer beaucoup d'autres. Tout le mérite de la découverte de la coloration propre de la rétine appartient à $M$. le professeur Boll, avec toutes ses conséquences, dont $M$. Kühne nous parait s'être prématurément emparé. $M$.

Appunn's tonometer. After tuning a note roughly to one of these, sharpen it till it beats four times in a second with the standard. Any temperament,
even Helmholtz's, the best in existence, can thus be easily and perfectly realised note by note.

$x$ Monatsbericht der königlichen preussischen Akademie der Wissenschaften zu Berlin, November, 1876 . Gesammtsitzung vom 23 November, 1876 , S. $78_{3}-787$.

${ }_{2}^{2}$ Annales a'O culistique, tome lxxvii., Janvier-Février $1877, \mathrm{pp}, 78-8 \mathrm{r}$ \$ 